\title{
Conserved properties of human and bovine prion strains on transmission to guinea pigs
}

\author{
Jiri G Safar ${ }^{1,2, *}$, Kurt Giles ${ }^{1,2}$, Pierre Lessard ${ }^{1}$, Frederic Letessier ${ }^{1}$, Smita Patel ${ }^{1}$, Ana Serban ${ }^{1}$, Stephen J DeArmond ${ }^{1,3}$ \\ and Stanley B Prusiner ${ }^{1,2}$
}

The first transmissions of human prion diseases to rodents used guinea pigs (Gps, Cavia porcellus). Later, transgenic mice expressing human or chimeric human/mouse PrP replaced Gps, but the small size of the mouse limits some investigations. To investigate the fidelity of strain-specific prion transmission to Gps, we inoculated 'type 1' and 'type 2' prion strains into Gps, and we measured the incubation times and determined the strain-specified size of the unglycosylated, protease-resistant ( $r$ ) PrP ${ }^{\mathrm{Sc}}$ fragment. Prions passaged once in Gps from cases of sporadic (s) CreutzfeldtJakob disease (CJD) and Gerstmann-Sträussler-Scheinker (GSS) disease caused by the P102L mutation were used, as well as human prions from a variant (v) CJD case, bovine prions from bovine spongiform encephalopathy (BSE) and mousepassaged scrapie prions. Variant CJD and BSE prions transmitted to all the inoculated Gps with incubation times of $367 \pm 4$ and $436 \pm 28$ days, respectively. On second passage in Gps, vCJD and BSE prions caused disease in $287 \pm 4$ and $310 \pm 4$ days, whereas SCJD and GSS prions transmitted in $237 \pm 4$ and $279 \pm 19$ days, respectively. Although hamster Sc237 prions transmitted to two of three Gps after 574 and 792 days, mouse-passaged RML and 301V prion strains, the latter derived from BSE prions, failed to transmit disease to Gps. Those Gps inoculated with vCJD or BSE prions exhibited 'type 2' unglycosylated, $\mathrm{rPrP}^{\mathrm{SC}}(19 \mathrm{kDa})$, whereas those receiving SCJD or GSS prions displayed 'type 1' prions (21 kDa), as determined by western blotting. Such strain-specific properties were maintained in Gps as well as mice expressing a chimeric human/mouse transgene. Gps may prove particularly useful in further studies of novel human prions such as those causing vCJD.

Laboratory Investigation (2011) 91, 1326-1336; doi:10.1038/labinvest.2011.89; published online 4 July 2011

KEYWORDS: BSE; GSS; guinea pig; prions; SCJD; vCJD

In the course of studies designed to develop sensitive assays for prions causing Creutzfeldt-Jakob disease (CJD) of humans, we asked whether novel strains of human prions might be transmitted to large rodents such as guinea pigs (Gps, Cavia porcellus). Gps were shown previously to be susceptible to prions causing sporadic (s) $\mathrm{CJD}^{1-3}$ and Gerstmann-Sträussler-Scheinker disease (GSS). ${ }^{4}$

After the initial reports of the transmission of SCJD to monkeys and apes, Gps were the first rodents to be shown to be susceptible to human prions. In 1975, two Gps were reported to have succumbed to an acute, rapidly progressive neurological disease at 422 and 512 days after combined intracerebral and intraperitoneal inoculation. ${ }^{2}$ An inoculum was prepared from the brain of one of the Gps and injected into $10 \mathrm{Gps}$, all of which developed disease with a mean incubation time of 216 days. On third passage, the mean incubation time for $27 \mathrm{Gps}$ was 231 days. $^{5}$

The biological diversity of prions is among their most remarkable features; this diversity is enciphered by $\operatorname{PrP}^{\mathrm{Sc}}$, the sole component of the prion. Strains of prions were initially identified in sheep with scrapie and later studied extensively in mice. ${ }^{6-8}$ For many years, the existence of prion strains was the most convincing argument that prions had to contain at least a short, specific sequence of nucleic acid; yet, none was ever found. Whether polyanions including RNA that stimulate protease-resistant PrP formation in vitro have an in vivo analog is unknown. ${ }^{9} 10$ Recent studies showed that numerous strains of prions can be prepared without RNA and

\footnotetext{
Institute for Neurodegenerative Diseases, University of California, San Francisco, CA, USA; ${ }^{2}$ Department of Neurology, University of California, San Francisco, CA, USA and ${ }^{3}$ Department of Pathology, University of California, San Francisco, CA, USA

Correspondence: Professor SB Prusiner, MD, Institute for Neurodegenerative Diseases, University of California, 513 Parnassus Avenue, HSE-774, San Francisco, CA 94143-0518, USA.

E-mail: stanley@ind.ucsf.edu

${ }^{*}$ Current address: Department of Pathology, Case Western Reserve University, Cleveland, OH, USA.

Received 9 December 2010; revised 17 March 2011; accepted 30 March 2011
} 
polyanions, and that modifying the stability of the amyloid polymers in the inocula gave rise to different synthetic prion strains. ${ }^{11-14}$ Additionally, modifying amyloid fibrils of PrP resulted in changes to the protease-resistant core of the protein. ${ }^{15}$

The identification of 'atypical' bovine spongiform encephalopathy (BSE) prions in Japan, the United States and Europe has enlarged the spectrum of BSE strains and forced a reconsideration of the issues on the origin of the British BSE epidemic. ${ }^{16-20}$ A report of a BSE-like strain in goats suggested that BSE transmission to other ungulates might not be a mere theoretical possibility; ${ }^{21}$ furthermore, the identification of a genetic case of $\mathrm{BSE}^{22}$ demonstrates that the full extent of the BSE epidemic is still unknown.

The biological characteristics and host range of prion strains are determined by the conformation of $\operatorname{PrP}^{\mathrm{Sc}}$ in the inoculum and the sequence of $\operatorname{PrP}^{\mathrm{C}}$ of the host. ${ }^{11,23-27}$ Studies with transgenic ( $\mathrm{Tg}$ ) mice ${ }^{28-33}$ established that sequence similarity between host $\mathrm{PrP}^{\mathrm{C}}$ and inoculum $\mathrm{PrP}^{\mathrm{Sc}}$ is an important factor in modulating susceptibility to infection. However, studies on ungulate and human prions demonstrated that some prion strains may elude the transmission barrier imposed by sequence differences. ${ }^{34,35}$ In cases of chimeric or mutated transgenes, susceptibility to prion infection may depend largely on the strain-specific conformation of $\mathrm{PrP}^{\mathrm{Sc}}$ in the inoculum. ${ }^{34,36,37}$

Although studies of genetically engineered mice have provided a wealth of information about prions, the small size of these animals limits studies of prions in blood and of brain imaging. To circumvent these problems, we examined Gps, which have blood volumes of $35-50 \mathrm{ml}^{38}$ and relatively large brains. To investigate the range of prion susceptibility, we inoculated Gps with variant (v) CJD, BSE, sCJD, GSS(P102L) and several rodent prion strains. Here, we report that vCJD and BSE prions transmitted efficiently to Gps, with incubation times of 350-450 days. Gps inoculated with BSE and vCJD prions showed similar patterns of spongiform degeneration in their brains that were distinct from those seen with inocula from patients who died of sCJD or the inherited disorder GSS(P102L). Our findings argue that prion transmission barriers are determined by a complex set of parameters involving species differences in PrP sequences as well as the conformation of $\operatorname{PrP}^{\mathrm{Sc}}$ that enciphers strain-specific traits. Gps may prove to be a valuable model for the study of prion diversity.

\section{MATERIALS AND METHODS Ethics Statement}

All studies presented here were reviewed and approved by the UCSF Institutional Animal Care and Use Committee.

\section{Gps and Tg Mice}

Weanling Hartley guinea pigs (strain code 051 ) were purchased from Charles River Laboratories (Wilmington, MA). Tg mice expressing HuPrP and chimeric MHu2M(M111V,M165V,E167Q) on the PrP-knockout background, respectively denoted $\operatorname{Tg}(\mathrm{HuPrP}) 440 / \mathrm{Prnp}^{0 / 0}$ and $\operatorname{Tg}(\mathrm{MHu} 2 \mathrm{M}, \mathrm{M} 111 \mathrm{~V}, \mathrm{M} 165 \mathrm{~V}$, E167Q) $1014 /$ Prnp $^{0 / 0}$ mice, have been previously reported. ${ }^{31,39}$

\section{Prion Isolates and Transmission Studies}

The brain sample of a vCJD case, which was diagnosed by immunohistochemistry and western immunoblotting, was kindly provided by Robert Will and James Ironside, National CJD Surveillance Unit, University of Edinburgh, UK. BSE isolate BBP12/92 was obtained from the Central Veterinary Laboratory, Weybridge, UK, and titrated in different laboratories by bioassays in cows, wt and $\mathrm{Tg}$ mice. ${ }^{40,41}$ The titer of BSE prions obtained by endpoint titration in Tg mice expressing bovine PrP was 7.1-7.7 log $\mathrm{ID}_{50} \mathrm{U} / \mathrm{g} .{ }^{40}$ Both sCJD and GSS prions, passaged first in Gps, were kindly provided by Jun Tateishi, Neurological Institute, Kyushu University, Fukuoka, Japan. sCJD prions were originally isolated from a 52-year-old female patient; GSS prions were originally isolated from a 61-year-old male carrying the $\operatorname{PrP}(\mathrm{P} 102 \mathrm{~L})$ mutation. The Sc237 strain was originally obtained from Richard $\mathrm{Marsh}^{42}$ and was passaged repeatedly in golden Syrian hamsters (LVG:Lak, Charles River Laboratories); Sc237 appears to be indistinguishable from strain $263 \mathrm{~K}^{43}$ The RML prion strain was derived from the Chandler isolate $^{44}$ passaged in $\mathrm{CD}-1$ mice. The $301 \mathrm{~V}$ prion strain, originally isolated from a cow infected with BSE, was obtained from $\mathrm{H}$ Fraser ${ }^{45}$ and maintained by serial passaging in B6.I mice. ${ }^{46}$

Brain homogenates for bioassay were prepared in PBS, $\mathrm{pH}$ 7.4, by three 75-s cycles in a reciprocal homogenizer Mini-BeadBeater-8 (BioSpec Products, OH). Weanling Gps were inoculated with $100 \mu \mathrm{l}$ of a $1 \%(\mathrm{wt} / \mathrm{vol})$ homogenate in sterile PBS without $\mathrm{Ca}^{2+}$ or $\mathrm{Mg}^{2+}$ by using a 27-gauge, disposable hypodermic needle inserted into the right parietal lobe. Following inoculation, the status of the Gps was monitored daily, whereas the neurological status was assessed three times per week. The clinical criteria used for diagnosis of scrapie in mice and hamsters, as previously described, ${ }^{28,47,48}$ were also used in scoring Gps.

\section{Brain Sample Preparation}

Brainstem tissue slices or brain macerates weighing 250 to $350 \mathrm{mg}$ were homogenized to a final $15 \%$ (wt/vol) in $4 \%$ (wt/vol) Sarkosyl in PBS, pH 7.4, by three 75-s cycles in a reciprocal homogenizer Mini-BeadBeater-8 (BioSpec Products). The resulting homogenate was diluted to a final $5 \%(\mathrm{wt} / \mathrm{vol})$ using PBS containing 4\% (wt/vol) Sarkosyl and $5 \mu \mathrm{g} / \mathrm{ml}$ of proteinase $\mathrm{K}$ (PK; unless stated otherwise) and incubated for $60 \mathrm{~min}$ at $37^{\circ} \mathrm{C}$ on the shaker. After a clarification spin at $500 \mathrm{~g}$ for $5 \mathrm{~min}$ at room temperature (RT) in a drum rotor (Jouan, Winchester, VA), the samples were mixed with stock solution containing $4 \%$ sodium phosphotungstate (NaPTA) and $170 \mathrm{mM} \mathrm{MgCl}$, pH 7.4, to obtain a final concentration of $0.32 \%$ NaPTA. After a 1-h incubation 
at $37^{\circ} \mathrm{C}$ on a rocking platform, the samples were centrifuged at $14000 \mathrm{~g}$ in a Jouan MR23i centrifuge for 15-30 min at RT. The resulting pellets were resuspended in $83 \mu \mathrm{l}$ of $\mathrm{H}_{2} \mathrm{O}$ containing protease inhibitors $(0.5 \mathrm{mM}$ phenylmethylsulfonyl fluoride (PMSF); aprotinin and leupeptin, $2 \mu \mathrm{g} / \mathrm{ml}$ each) and assayed by western blotting or the conformation-dependent immunoassay (CDI).

Alternatively, 10\% (wt/vol) homogenates from Tg mouse brains were prepared in PBS using a Precellys 24 bead-beater (MO BIO, Carlsbad, CA), with 2 cycles of $75 \mathrm{~s}$ each at speed $6200 \mathrm{rpm}$, with a 5-min interval between runs. Samples were then treated with $100 \mu \mathrm{g} / \mathrm{ml} \mathrm{PK}$ for $60 \mathrm{~min}$ at $37^{\circ} \mathrm{C}$, and digestion was terminated by the addition of $2 \mathrm{mM}$ PMSF.

\section{Muscle and Tongue Tissue Preparation}

For biochemical analysis only, slices from different $\mathrm{Gp}$ muscles or cuts of tongue weighing $250-350 \mathrm{mg}$ were homogenized to a final $15 \%$ (wt $/ \mathrm{vol})$ in $4 \%$ (wt/vol) Sarkosyl in PBS, pH 7.4, containing $3 \mathrm{mM} \mathrm{CaCl}_{2}$ and $5 \mathrm{mM} \mathrm{MgCl}_{2}$, by one 75-s cycle in a reciprocal homogenizer Mini-BeadBeater8 (BioSpec Products), as described. ${ }^{49,50}$ Resulting muscle homogenates were incubated on a rotating wheel for $3 \mathrm{~h}$ at $37^{\circ} \mathrm{C}$ with $1 \mathrm{mg} / \mathrm{ml}$ of Collagenase type 4 (Worthington Biochemical, Lakewood, NJ), rehomogenized by six 75-s cycles and precipitated for $1 \mathrm{~h}$ at $37^{\circ} \mathrm{C}$ with $1.28 \%$ (wt/vol) NaPTA, as described. ${ }^{26,50}$ After a $30-$ min centrifugation at $14000 \mathrm{~g}$, the resulting pellets were resuspended in $83 \mu \mathrm{l}$ of PBS, pH 7.4, containing a protease-inhibitor cocktail (0.5 mM PMSF and $2 \mu \mathrm{g} / \mathrm{ml}$ each of aprotinin and leupeptin). Tissues were then assayed by CDI and western blotting.

\section{Western Blots}

The PTA pellets precipitated from the tissue homogenates were mixed with an equal volume of SDS-loading buffer and boiled for $5 \mathrm{~min}$; $30-\mu \mathrm{l}$ samples were loaded on two $12.5 \%$ Tris-glycine SDS-PAGE Novex gels (Invitrogen, Carlsbad, CA). Each western blot was incubated with $0.75 \mu \mathrm{g} / \mathrm{ml}$ of $\mathrm{mAb} 3 \mathrm{~F} 4^{51}$ for $2 \mathrm{~h}$ at RT. After extensive washing, the blots were developed with peroxidase-labeled, anti-mouse Fc secondary antibody and by the enhanced chemiluminescence system, as described. ${ }^{36}$ Samples that had not been precipitated with PTA were run on precast 10\% NuPAGE Novex Bis-Tris gels and transferred using the iBlot Dry Blotting system, as previously described. ${ }^{39}$

\section{Histopathology}

Brain tissue was either immediately frozen or immersionfixed in $10 \%$ buffered formalin for embedding in paraffin. Eight-micrometer-thick sections were stained with hematoxylin and eosin to evaluate vacuolation. Evaluation of reactive astrocytic gliosis was performed by GFAP immunostaining using a rabbit antiserum (Dako, Carpinteria, CA). Hydrolytic autoclaving pretreatment of the formalin-fixed tissue sections and mAb 3F4 were used to detect $\operatorname{PrP}^{\mathrm{Sc}}$, as described previously. ${ }^{52}$

\section{RESULTS}

\section{Primary Structure of GpPrP}

When we initiated transmission studies of human prions into Gps, only two fragmentary sequences of GpPrP had been deposited in the GenBank database (Accession numbers AY133039 and AF139166). Therefore, we sequenced DNA extracted from the blood of Hartley guinea pigs (strain code 051, Charles River Laboratories; Figure 1). Subsequently, an entire GpPrP sequence was published, which differed from the Hartley Gp at residue 62. Premzl et al ${ }^{53}$ reported a serine encoded at position 62, whereas we found a glycine. This polymorphism was also observed in the two deposited fragmentary sequences: GenBank AY133039 reported serine 62 and AF139166 had glycine 62. From these sequencing data, the Gp was placed in the mammalian PrP gene tree next to the rabbit and pika. ${ }^{54}$

Additionally, GpPrP lacks 11 residues in the N-terminal region preceding the octapeptide repeats. Within the central PrP region between residues 96-167 (mouse (Mo) numbering), which has been proposed to have a major role in determining the species barrier, ${ }^{55} \mathrm{GpPrP}$ differs from human (Hu) PrP and bovine (Bo) PrP at 6 and 4 positions, respectively. The polymorphic human codon 129 most commonly expresses methionine, as do GpPrP and BoPrP at their corresponding residue numbers.

From studies of $\mathrm{Hu} / \mathrm{Mo}$ chimeric PrP, we learned that six human residues between positions 96 and 167 are critical for the transmission of human prions in Tg mice. ${ }^{37,39}$ Comparing these and surrounding residues in Gp, Mo and $\mathrm{Hu}$ PrP, we found that five of six critical residues that feature in transmission of human prions to mice are either identical or quite similar in $\mathrm{Gp}$ and $\mathrm{Hu} \operatorname{PrP}$ (Figure 1). At residues 108, 142 and 144, the amino acids are identical in GpPrP and $\mathrm{HuPrP}$; at residue 137, the amino acid is quite similar, with leucine encoded in GpPrP and an isoleucine in HuPrP. The two PrPs are also similar at residue 154, where the aromatic amino acid tyrosine is encoded in GpPrP and another aromatic residue histidine is found in HuPrP.

\section{Transmission of Prions to Gps}

To determine the susceptibility of Gps to prion isolates from different species, we inoculated Gps intracerebrally with human vCJD and bovine BSE prions, as well as sCJD and GSS prions already passaged once in Gps; in addition, Syrian hamster (SHa) Sc237 prions as well as RML and 301V mouse prions were injected into Gps (Table 1). The $301 \mathrm{~V}$ strain was isolated in $\operatorname{Prnp}^{\mathrm{b} / \mathrm{b}}$ mice by passaging of BSE prions. ${ }^{56}$ Variant CJD and BSE inocula were prepared as $1 \%$ homogenates from the brain tissue from an autopsied vCJD patient and from the brainstem of a BSE-infected cow, respectively. Variant CJD and BSE prions transmitted to Gps with 100\% efficiency, with mean incubation times of 367 and 436 days, respectively. Upon second passage in Gps, the incubation periods for vCJD and BSE prions shortened to 287 days and 310 days, respectively (Figure 2). Similar incubation times 


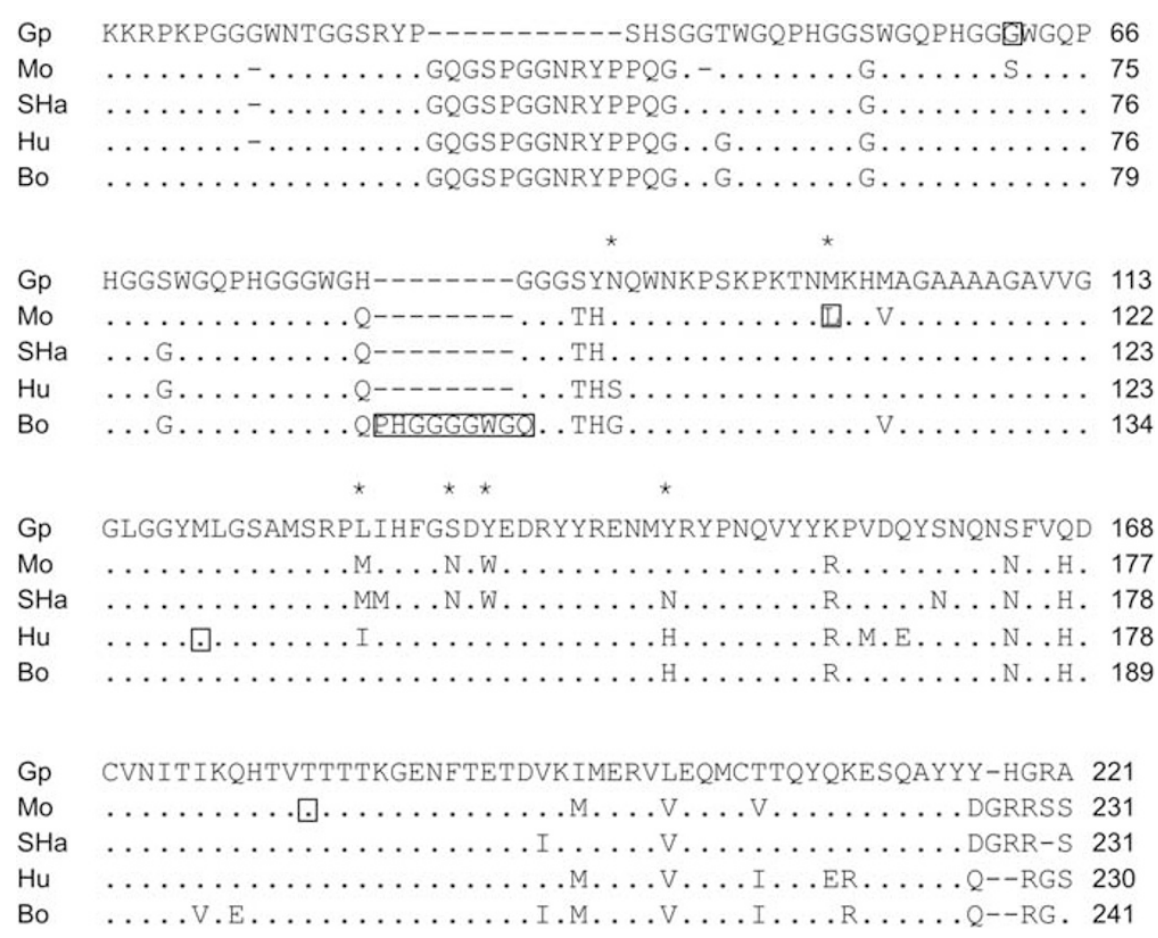

Figure 1 Sequence alignment of mature guinea pig (Gp)PrP compared with those of mouse (Mo), Syrian hamster (SHa), human (Hu) and bovine (Bo) PrP; only residues that differ from GpPrP are shown. N- and C-terminal signal sequence cleavage sites were predicted using SignalP ${ }^{74}$ and big-PI Predictor, ${ }^{75}$ respectively. Predictions were in agreement with experimentally determined signal peptide cleavage positions. Residue numbers are given for each sequence from the $\mathrm{N}$ terminus of the immature protein. Asterisks indicate residues important for the transmission of human prions to mice; polymorphic residues are shown by boxes.

Table 1 Transmission of prions to guinea pigs

\begin{tabular}{lcl}
\hline Inoculum & $\begin{array}{c}\text { Mean incubation } \\
\text { time } \pm \text { s.e.m. (days) }\end{array}$ & $n / n_{0}{ }^{a}$ \\
& $367 \pm 4$ & \\
\hline vCJD & $287 \pm 4$ & $4 / 4$ \\
vCJD > Gp (second passage) & $436 \pm 28$ & $5 / 5$ \\
BSE & $310 \pm 4$ & $4 / 4$ \\
BSE $>$ Gp (second passage) & - & $6 / 6$ \\
SCJD & $237 \pm 4$ & $5 / 12^{b}$ \\
sCJD $>$ Gp (second passage) & $242 \pm 9$ & $3 / 3$ \\
sCJD $>$ Gp $>$ Gp (third passage) & - & $5 / 5$ \\
GSS & $279 \pm 19$ & $1 / 23^{c}$ \\
GSS $>$ Gp (second passage) & $204 \pm 22$ & $4 / 4$ \\
GSS $>$ Gp $>$ Gp (third passage) & $683 \pm 109$ & $6 / 6$ \\
Sc237 & $>850$ & $2 / 3^{d}$ \\
RML & $>850$ & $0 / 3$ \\
$301 V$ & & $0 / 4$
\end{tabular}

\footnotetext{
${ }^{a}$, number of ill Gps; $n_{0}$, number of Gps under observation.

${ }^{\mathrm{b}}$ Aggegate data from multiple studies. The five ill animals developed signs of neurological dysfunction between 381 and $652 \mathrm{dpi}^{1-3}$

${ }^{c}$ Each of four cases of GSS was inoculated in four to nine guinea pigs. Only one animal developed illness, but the incubation period was not reported. ${ }^{4}$

dwo Gps became ill at 574 and 792 dpi; the third Gp showed no signs of disease at $850 \mathrm{dpi}$, when the experiment was terminated.
}

were observed upon second and third passages of sCJD and GSS prions in Gps. In contrast, SHa Sc237 prions transmitted to two of three Gps, with incubation times of 574 and 792 days. Neither RML nor $301 \mathrm{~V}$ mouse prions transmitted to Gps within the 850-day observation period. From these findings, we concluded that Gps are more susceptible to vCJD and BSE prions than either SCJD or GSS(P102L) prions on primary transmission. After passage in Gps, these different prion inocula gave similar incubation periods.

\section{Evidence for Propagation of Different Prion Strains in Gps}

After passage in Gps, human vCJD, sCJD and GSS(P102L) prions, as well as bovine BSE prions were analyzed by western immunoblotting. Passage of vCJD and BSE prions in Gps produced type $2 \mathrm{rPrP}^{\mathrm{Sc}}$ as demonstrated by the approximately 19-kDa, unglycosylated $\operatorname{PrP}$ band (Figure 3, lanes 2 and 4). In contrast, passage of sCJD and GSS in Gps yielded type $1 \mathrm{rPrP}^{\mathrm{Sc}}$ as shown by the approximately $21-\mathrm{kDa}$, unglycosylated PrP bands (Figure 3, lanes 6 and 8).

\section{Neuropathology of Prion Disease in Gps}

Neuropathological analysis of brains from prion-infected Gps demonstrated that Gps replicate many of the neuropathological features of humans with sCJD, GSS and vCJD, as well as those found in cattle with BSE. In the brains of Gps 

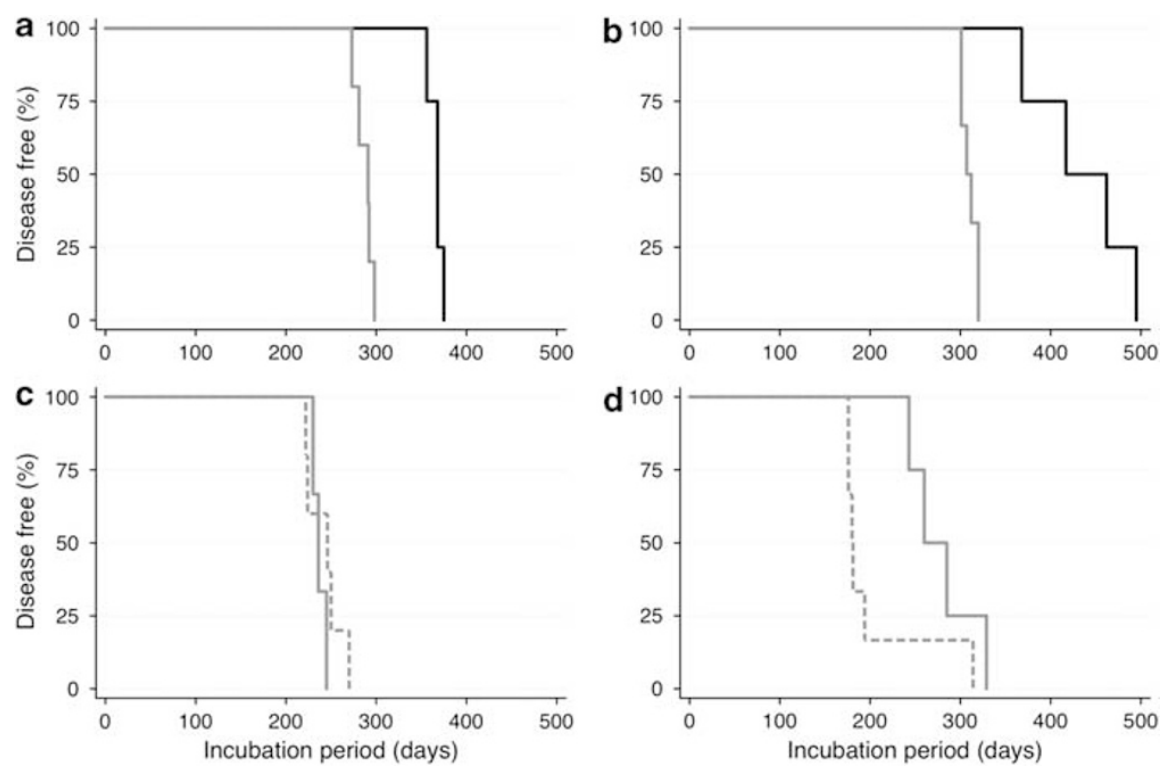

Figure 2 Serial passage of (a) vCJD, (b) BSE, (c) SCJD and (d) GSS prions in Gps. Weanling Gps were inoculated with $100 \mu$ l of a $1 \%$ (wt/vol) homogenate in sterile PBS without $\mathrm{Ca}^{2+}$ or $\mathrm{Mg}^{2+}$ by using a 27-gauge, disposable hypodermic needle inserted into the right parietal lobe. Following inoculation, the status of the Gps was monitored daily, whereas the neurological status was assessed three times per week. Kaplan-Meier survival curves were drawn from first (solid black), second (solid gray) and third (dashed gray) passages.

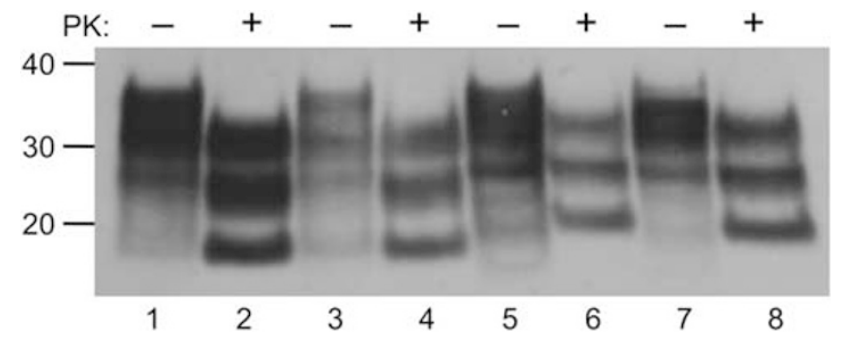

Figure 3 Human and bovine prions passaged in Gps retained their strain type. Western blot of Gp brain homogenate before (odd lanes) or after (even lanes) treatment with $10 \mu \mathrm{g} / \mathrm{ml}$ of PK for $1 \mathrm{~h}$ at $37^{\circ} \mathrm{C}$. First passage of vCJD (lanes 1 and 2) and BSE (lanes 3 and 4) prions in Gps resulted in type 2 strains, characterized by an approximately 19-kDa unglycosylated band. In contrast, second passage of SCJD (lanes 5 and 6) and GSS (lanes 7 and 8) prions in Gps resulted in type 1 strains, characterized by approximately 21-kDa unglycosylated bands. Apparent molecular masses based on protein standards are shown in kilodaltons.

inoculated with Gp-passaged sCJD prions, vacuolation and finely granular $\mathrm{PrP}^{\mathrm{Sc}}$ deposition were seen, similar to humans with SCJD (Figure 4a and b). Inoculation with Gp-passaged GSS(P102L) prions resulted in delicate gray matter vacuolation and granular $\mathrm{PrP}^{\mathrm{Sc}}$ deposits in $\mathrm{Gp}$ brain (Figure $4 \mathrm{c}$ and d), a neuropathological phenotype resembling that of CJD, as previously observed when GSS prions were passaged in nonhuman primates. ${ }^{57}$ Transmission of vCJD to Gps produced a phenotype similar to vCJD in humans, with large multilobulated vacuoles (Figure 4e) and large, coarse $\operatorname{PrP}^{\mathrm{Sc}}$ deposits (Figure 4f). Additionally, PrP immunostaining of astrocytes, unique to vCJD and BSE infection, were found in Gps inoculated with vCJD and BSE prions (Figure $4 \mathrm{~g}$ and $\mathrm{k}$ ).
In Gps inoculated intracerebrally with BSE prions, large clusters of vacuoles were found (Figure 4h). Both finely granular and large, coarse $\operatorname{PrP}^{\mathrm{Sc}}$ deposits were found in the neocortex, hippocampus, diencephalon and brainstem (Figure 4i). Similar to BSE in cattle, ${ }^{58,59} \mathrm{PrP}^{\mathrm{Sc}}$ accumulated in the cell bodies of neurons in the caudal pons and medulla in BSE-infected Gps (Figure 4j). Neuropathological changes in Gps infected with BSE prions were severe in multiple cerebral hemisphere and brainstem regions, which contrasts with cattle orally infected with BSE prions, where neuropathological changes are generally concentrated in the brainstem. Differences in the anatomical distribution of $\operatorname{PrP}^{\mathrm{Sc}}$ might be due to different ports of entry of BSE prions. ${ }^{60}$

\section{Transmission of Gp-passaged Prions to Tg Mice}

Western blots of samples from Gp brains were analyzed to determine the electrophoretic mobility of protease-resistant $\mathrm{PrP}^{\mathrm{Sc}}$ fragments ( $\left.\operatorname{PrP} 27-30\right)$. As shown in Figure 5 (lanes 3-5), the unglycosylated $\mathrm{rPrP}^{\mathrm{sc}}$ fragment from $\mathrm{Gp}$ brains inoculated with Gp-passaged sCJD and GSS prions migrated at a higher molecular weight (type 1) and that from Gp brains inoculated with vCJD prions migrated at a lower molecular weight (type 2). These electrophoretic mobilities mirrored those found in human brains (Figure 5, lanes 1 and 2).

To determine whether the strain-specific characteristics of human prions were retained after passage in Gps, we inoculated samples into $\mathrm{Tg}(\mathrm{HuPrP}) 440 / \operatorname{Pr}^{0 / 0} p^{0}$ and chimeric $\operatorname{Tg}\left(\right.$ MHu2M,M111V,M165V,E167Q) 1014/Prnp ${ }^{0 / 0}$ mice. In both $\mathrm{Tg}$ lines, incubation periods for Gp-passaged sCJD prions were increased by $\sim 50 \%$ (Table 2 ). The type $1 \mathrm{rPrP}^{\mathrm{sc}}$ 

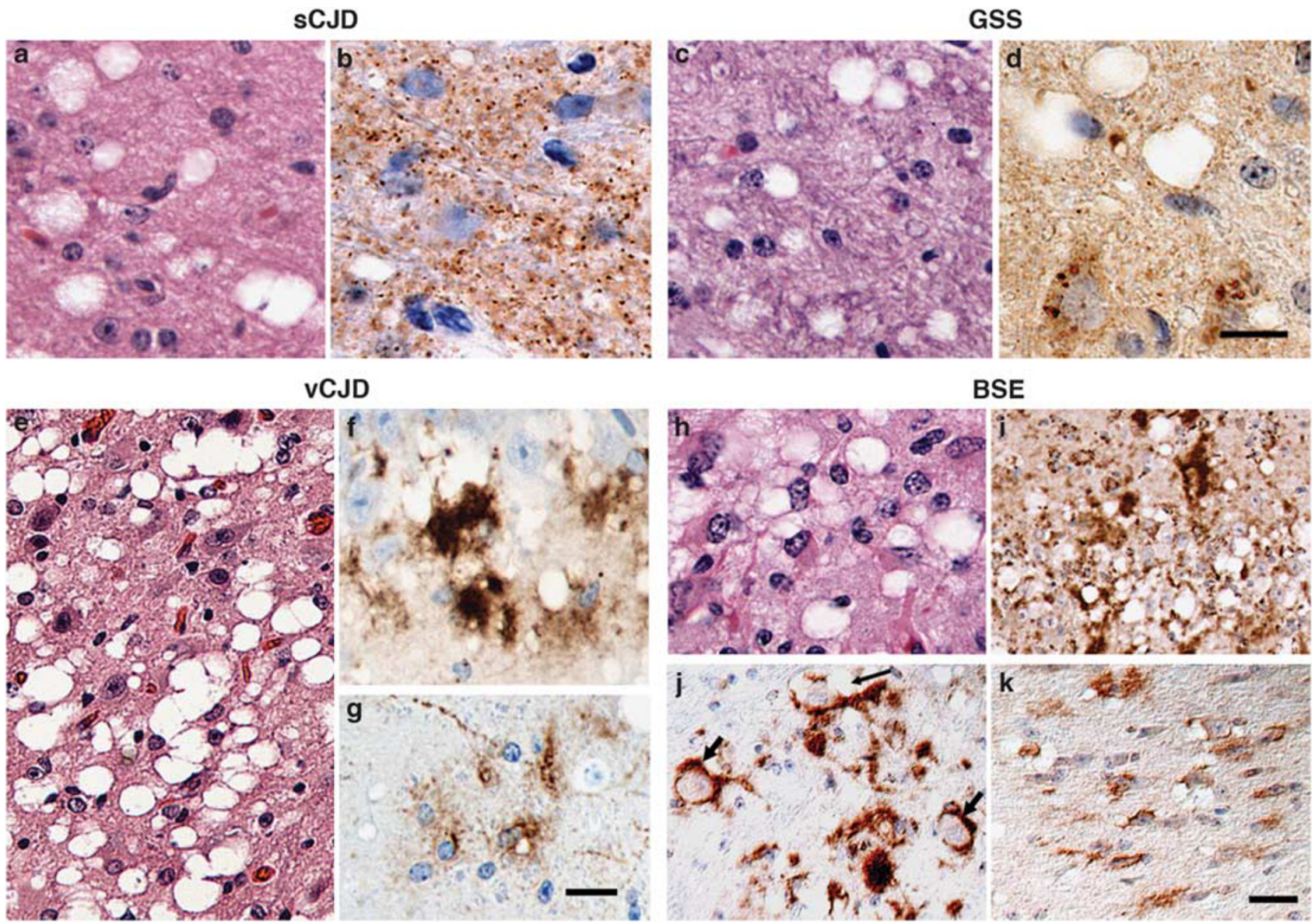

Figure 4 Transmission of human-derived SCJD $(\mathbf{a}, \mathbf{b})$, GSS (c, $\mathbf{d})$ and vCJD $(\mathbf{e}-\mathbf{g})$ prions, and cattle-derived BSE prions (h-k) to Gps accurately reproduces the vacuolation and $\mathrm{PrP}^{\mathrm{SC}}$ deposition phenotypes observed in humans and cattle. Brain sections stained with hematoxylin and eosin show vacuolation from all inocula (a, $\mathbf{c}, \mathbf{e}, \mathbf{h})$. GSS (c) and BSE (h) prions resulted in vacuolation profiles similar to that from SCJD prions (a). Vacuoles from the vCJD inoculum were large and multiloculated (e). Immunohistochemistry using the 3F4 antibody revealed that PrP ${ }^{\mathrm{Sc}}$ deposits were finely granular for sCJD (b); both fine (3-6 $\left.\mu \mathrm{m}\right)$ and large $(30-80 \mu \mathrm{m})$ for BSE prions (i); coarse for vCJD prions (f); the coarse PrP ${ }^{\mathrm{Sc}}$ deposits did not bind thioflavin S, indicating they were not mature amyloid plaques (data not shown). Following BSE inoculation, many neuronal cytoplasmic PrP ${ }^{\mathrm{Sc}}$ inclusions (short arrows) and intraneuronal vacuoles (long arrow; $\mathbf{j}$ ) were seen in the reticular formation of the pons. Astrocytes were immunopositive for PrPSc in the pontine white matter after BSE transmission (k) and in the white matter after vCJD inoculation (g). Bar in d represents $20 \mu \mathrm{m}$ and also applies to b. Bar in $\mathbf{g}$ represents $20 \mu \mathrm{m}$ and also applies to a, $\mathbf{c}, \mathbf{f}$ and $\mathbf{h}$. Bar in $\mathbf{k}$ represents $40 \mu \mathrm{m}$ and also applies to $\mathbf{e}, \mathbf{i}$ and $\mathbf{j}$.

phenotype (21-kDa PrP band) found in the human sCJD brain and after passage in Gps was also observed after passage in Tg1014 mice (Figure 5). Although vCJD prions transmitted to $\mathrm{Tg} 1014$ mice, they did not produce disease in the Tg440 mice. Similar to SCJD prions passaged in Gps and then to Tg1014 mice, vCJD prions passaged in Gps also produced longer incubation periods in Tg1014 mice (Table 2). As shown in Figure 5, the type $2 \mathrm{rPrP}^{\mathrm{Sc}}$ phenotype (19-kDa PrP band) found in the human vCJD brain and after passage in Gps was also observed after serial transmission to Tg1014 mice. Moreover, although vCJD produced both type 1 and type $2 \mathrm{rPrP}^{\mathrm{Sc}}$ in $\mathrm{Tg} 1014$ mice depending on the incubation period, ${ }^{39}$ seven of seven $\mathrm{Tg} 1014$ mice inoculated with Gp-passaged vCJD exhibited type $2 \mathrm{rPrP}^{\mathrm{Sc}}$.

Second passage of GSS (P102L) prions in Gps produced the type 1 unglycosylated $\mathrm{rPrP}^{\mathrm{Sc}}$ phenotype (21-kDa PrP band), which was found in $\sim 70 \%$ of GSS cases (Figures 3 and 5). ${ }^{61}$
Unfortunately, the original human GSS prion sample used in primary passage in Gps was not available for direct comparison. ${ }^{4}$ From the results of the foregoing studies, we concluded that strain-specified conformations of human prions were maintained during passage in Gps.

\section{Relative PrP ${ }^{\mathrm{Sc}}$ Levels in Brain, Skeletal Muscle and Tongue of Gps}

Using western immunoblotting and the CDI, we determined the relative $\mathrm{PrP}^{\mathrm{Sc}}$ levels in the brains, skeletal muscles and tongues of Gps inoculated with human vCJD prions and BSE prions, as well as sCJD and GSS(P102L) prions passaged in Gps. In the brains of Gps displaying neurological dysfunction, similar levels of $\mathrm{PrP}^{\mathrm{Sc}}$ were found regardless of the inoculum (Figures 3 and 5). No $\operatorname{PrP}^{\mathrm{Sc}}$ was found in the skeletal muscles of Gps infected with vCJD, BSE or Gp-passaged sCJD or GSS prions, as determined by CDI (Figure 6). 


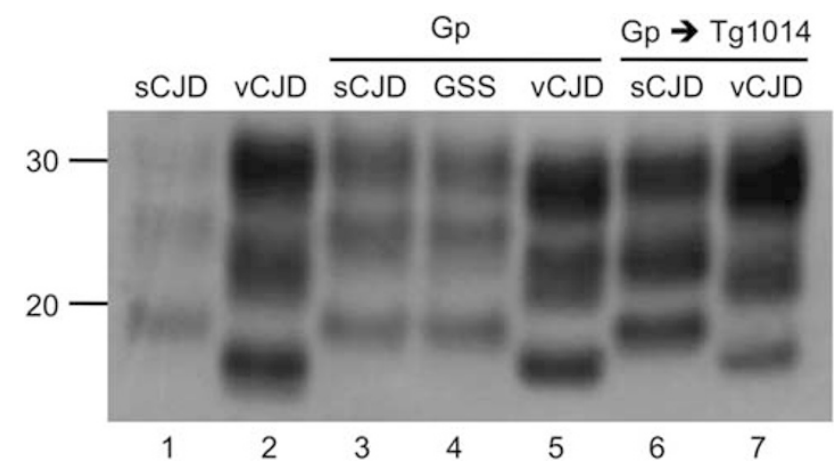

Figure 5 Western blot shows that the strain type of human prions was retained upon passage in Gps and transgenic mice. SCJD and vCJD prions before (lanes 1 and 2) and after transmission to Gps (lanes 3 and 5); homogenates from ill Gps were then transmitted to $\mathrm{Tg}(\mathrm{MHu} 2 \mathrm{M}, \mathrm{M} 111 \mathrm{~V}$, M165V,E167Q) 1014 mice (lanes 6 and 7). Human GSS prions were also transmitted to Gps (lane 3). Type $1 \mathrm{PrP}^{\mathrm{Sc}}$ from $\mathrm{SCJD}$ and type $2 \mathrm{PrP}^{\mathrm{Sc}}$ from vCJD were maintained upon passage in Gps and Tg mice. Apparent molecular masses based on migration of protein standards are shown in kilodaltons.

Table 2 Transmission of Gp-passaged sCJD and vCJD prions to $\mathrm{Tg}(\mathrm{MHu2M}, \mathrm{M111V}, \mathrm{M165V}, \mathrm{E} 167 \mathrm{Q}) 1014 / \mathrm{Prnp}^{0 / 0}$ and Tg(HuPrP)440/Prnp ${ }^{0 / 0}$ mice

\begin{tabular}{|c|c|c|c|c|}
\hline \multirow[t]{2}{*}{ Inoculum } & \multicolumn{2}{|c|}{$\operatorname{Tg} 1014$} & \multicolumn{2}{|c|}{$\operatorname{Tg} 440$} \\
\hline & $\begin{array}{c}\text { Mean } \\
\text { incubation } \\
\text { time } \pm \text { s.e.m. } \\
\text { (days) }\end{array}$ & $n / n_{0}$ & $\begin{array}{c}\text { Mean } \\
\text { incubation } \\
\text { time } \pm \text { s.e.m. } \\
\text { (days) }\end{array}$ & $n / n_{0}$ \\
\hline$s C J D$ & $78 \pm 2^{\mathrm{a}}$ & $18 / 18$ & $169 \pm 3^{b}$ & $24 / 24$ \\
\hline $\begin{array}{l}\mathrm{sCJD}>\mathrm{Gp}>\mathrm{Gp} \\
\text { (third passage) }\end{array}$ & $123 \pm 3$ & $16 / 16$ & $278 \pm 28$ & $8 / 8$ \\
\hline$v C J D$ & $210 \pm 16^{a}$ & $14 / 14$ & $>500^{b}$ & $0 / 16$ \\
\hline$v C J D>G p$ & $272 \pm 14$ & $7 / 7$ & $>600$ & $0 / 7$ \\
\hline
\end{tabular}

(second passage)

\footnotetext{
${ }^{\mathrm{a}}$ Data previously reported in Giles et al. ${ }^{39}$
}

bata previously reported in Korth et al. ${ }^{37}$

Western blotting was inconclusive with traces of $\mathrm{PrP}^{\mathrm{Sc}}$-like signals sometimes seen in skeletal muscles (data not shown).

In the tongues of terminal Gps, those inoculated with either vCJD or BSE prions gave low CDI signals that were above background; the respective CDI values were 140 -fold and 220-fold lower than those in brain (Figure 6, compare panels $\mathrm{d}$ with a). To determine whether the low CDI signals in tongue were $\mathrm{PrP}^{\mathrm{Sc}}$, we performed western blotting. As shown in Figure 7, no shift in the molecular size of $\operatorname{PrP}^{\mathrm{Sc}}$ after limited PK digestion was found, arguing that bioassays will need to be performed to determine the level, if any, of prions in $\mathrm{Gp}$ tongue.

\section{DISCUSSION \\ Maintenance of Prion Strain Characteristics upon Transmission of Human Prions to Gps}

The susceptibility of Gps to vCJD prions was unexpected because of the poor transmission of human prions to most rodents. Initial attempts to transmit kuru and CJD prions to Gps were unsuccessful. ${ }^{1}$ Subsequent studies succeeded in infecting two Gps, 422 and 512 days after inoculation with a biopsy sample from a patient who later died of CJD. ${ }^{2}$ Two additional cases of CJD were inefficiently transmitted to Gps, with long incubation periods: for case one, one of four animals died at 652 days and for case two, two of four animals succumbed at 381 and 382 days. $^{3}$ However, it is notable that these transmission studies were performed before $\operatorname{Pr} \mathrm{P}^{\mathrm{Sc}}$ was discovered and human prion strains were appreciated; the genotype and strain type of these inocula are unknown, making it difficult to relate the results to our findings. Transmission of GSS(P102L) prions to Gps was even less efficient than CJD, with only 1 of 23 animals, inoculated with one of four GSS cases, succumbing to disease. ${ }^{4}$ Notably, the GSS phenotype and molecular characteristics of $\operatorname{PrP}^{\mathrm{Sc}}$ vary considerably; to date, transmitted GSS cases harbor the P102L mutation and type $1 \mathrm{PrP}^{\mathrm{Sc}}{ }^{62-64}$ Here, we report that human vCJD prions transmitted to Gps $\sim 350$ days after inoculation. Upon serial passage, vCJD prions had similar incubation periods for sCJD and GSS prions, of $\sim 250$ days (Figure 2). We attempted to transmit two different strains of mouse prions to Gps, but were not successful (Table 1).

Western immunoblotting showed that the molecular size of the unglycosylated PrP 27-30 fragment after limited proteolysis was maintained upon passage of sCJD, GSS and vCJD prions through Gps (Figures 3 and 5). Although the Gp-passaged CJD upon transmission to Tg1014 mice mirrored the glycosylation and type $1 \operatorname{PrP}^{\mathrm{Sc}}$ pattern observed with the primary inoculum of type $1 \mathrm{sCJD}$, neither the full PRNP sequences nor western blots of the original GSS and SCJD cases were available for comparison because the neuropathological diagnosis was performed in Japan 30 years ago. Modern neuropathological classification of SCJD and GSS based on sequencing of the PRNP gene, immunohistochemistry for $\mathrm{PrP}^{\mathrm{Sc}}$ and patterns of $\mathrm{PrP}^{\mathrm{Sc}}$ on highresolution western blots evolved gradually over the past $\sim 10$ years. ${ }^{65}$ As the original human tissues were not available for these analyses and reisolation, these proof-of-principle experiments will have to be refined with other cases of GSS and SCJD, characterized by these modern methods. In addition, many features of human $\operatorname{PrP}^{\mathrm{Sc}}$ immunostaining and neuropil vacuolation were maintained on passage through Gps (Figure 4). Gp-passaged human prions also had similar transmission characteristics of the original strains (Tables 1 and 2, Figure 5). All Tg1014 mice inoculated with Gp-passaged vCJD had a type 2 strain analogous to vCJD, in contrast to a mixture of type 1 and type 2 strains, which was observed after inoculation of vCJD in Tg1014 mice. ${ }^{39}$ These 

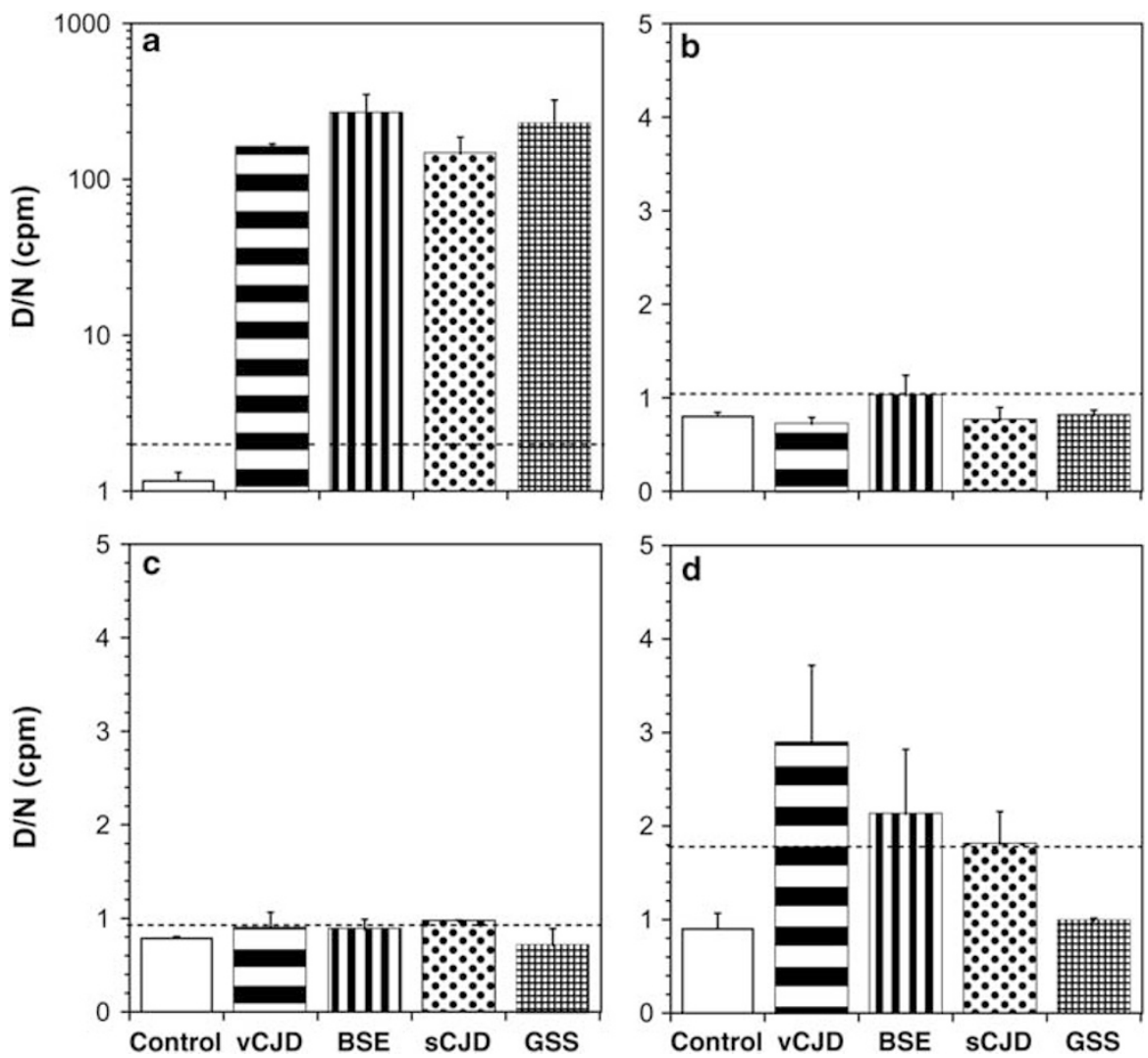

Figure 6 CDI measurements of PrP ${ }^{S c}$ in (a) brains, (b) forelimb muscles, (c) hindlimb muscles and (d) tongues of Gps after first passage of vCJD and BSE prions or second passage of SCJD and GSS prions. Gps were inoculated intracerebrally with $1 \%$ brain homogenates prepared from human brain infected with vCJD prions, bovine brain with BSE or Gp brain infected with either SCJD or GSS(P102L) prions. As a control, tissues from an age-matched, non-infected $\mathrm{Gp}$ were analyzed. The concentration of PrP ${ }^{\mathrm{Sc}}$ was measured using recFab HuM D18 to capture and Eu-labeled mAb 3F4 to detect GpPrP. Muscle homogenates were incubated with $1 \mathrm{mg} / \mathrm{ml}$ of collagenase for $3 \mathrm{~h}$ at $37^{\circ} \mathrm{C}$. Samples were subjected to limited digestion with $10 \mu \mathrm{g} / \mathrm{ml}$ of PK for $1 \mathrm{~h}$ at $37^{\circ} \mathrm{C}$ and then precipitated with PTA. The dashed lines indicate the upper normal limit (cutoff values) calculated as (mean $+(3 \times \mathrm{s} . \mathrm{d}$.)) from tissues taken from age-matched, control Gps. The results obtained with samples taken from three Gps are expressed as the mean \pm s.d.; each sample was tested two or four times by the $\mathrm{CDI}$. The concentration of $\mathrm{PrP}^{\mathrm{Sc}}$ is proportional to the $(\mathrm{D} / \mathrm{N})$ value, measured as the time-resolved fluorescence in counts per minute $(\mathrm{cpm})$ from denatured (D) and native (N) samples; ${ }^{26,49}$ values exceeding the cutoff indicate the presence of $\operatorname{PrP}^{\mathrm{Sc}}$.

observations suggest that the GpPrP sequence may stabilize the type 2 conformation.

\section{GpPrP Sequence}

The degree of identity among the Gp, Hu and Bo PrP sequences within residues 96 and 154 , which are thought to be critical for the transmission of human prions to $\mathrm{Tg}$ mice, is strikingly similar (Figure 1). In studies of mice expressing chimeric $\mathrm{Mo} / \mathrm{Hu} \mathrm{PrP}$ transgenes, we found that the incubation times for transmission of sCJD prions could be reduced from over 200 to $\sim 110$ days by reverting $\mathrm{Hu}$ residues 165 and 167 to $\mathrm{Mo}^{37}$ we designated those mice as $\mathrm{Tg}$ (MHu2M,M165V,E167Q) mice. In recent studies, we found that reverting residue 111 in $\mathrm{Tg}(\mathrm{MHu} 2 \mathrm{M}, \mathrm{M} 111 \mathrm{~V}, \mathrm{M} 165 \mathrm{~V}$, E167Q) mice shortened the incubation period for human prions to $\sim 80$ days. ${ }^{39}$ Residue 111 is methionine in both Gp and $\mathrm{Hu} \mathrm{PrP}$ but valine in Mo and Bo PrP.

Inocula prepared from the brains of one $\mathrm{vCJD}$ and one BSE case showed 100\% transmission rates and mean incubation times of 367-436 days. On second passage, the incubation time decreased to 287 days for vCJD prions and to 310 days for BSE prions (Figure 2). This shortening of the incubation time suggests some species-barrier effect probably due to the differences in the PrP sequences.

Interestingly, Gps were resistant to two different strains of mouse prions, RML and 301V (Table 1). The RML strain was propagated in $\operatorname{Prnp}^{\mathrm{a} / \mathrm{a}}$ mice that encode leucine at residue 108 , and $301 \mathrm{~V}$ prions were replicated in $\operatorname{Prnp}^{\mathrm{b} / \mathrm{b}}$ mice that specify phenylalanine at this position. In contrast, Gp, Bo and Hu PrP express methionine at residue 108. Whether the poor transmission of mouse prions to Gps can be ascribed to residue 108 remains to be determined. As BSE prions transmitted efficiently to Gps, a finding that has been independently confirmed by another group, ${ }^{66}$ the lack of $301 \mathrm{~V}$ prion transmission underscores the argument that this strain is a poor model for BSE ${ }^{67}$ Of note, SHaPrP also expresses methionine at position 108 (Figure 1), but SHa prions transmitted to two of three Gps after longer 


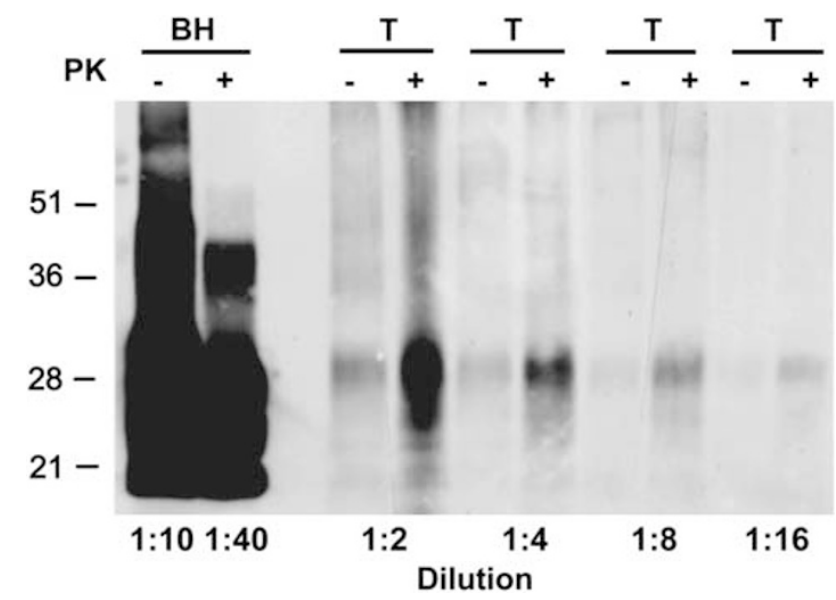

Figure 7 Western immunoblotting of tongue (T) from a BSE prion-infected Gp. PrP $\mathrm{PC}^{\mathrm{Sc}}$ in brain homogenate $(\mathrm{BH})$ of a BSE-infected $\mathrm{Gp}$ is shown for comparison. Brain and tongue tissues were serially diluted with SDS sample buffer at the indicated ratios to allow the same film exposure. Samples were either subjected to limited digestion with PK $(+)$ or left undigested $(-)$ and then precipitated with PTA, as described in Figure 6. PTA pellets were resuspended in $150 \mu \mathrm{l}$ of $2 \times$ SDS sample buffer. $^{76}$ Equal volumes of undigested and digested samples were boiled for $5 \mathrm{~min}$ before electrophoresis. SDS gel electrophoresis and western blotting were performed, as previously described. ${ }^{77}$ PrP was detected with the mAb 3F4 and developed with the enhanced chemiluminescent detection system (Amersham Biosciences). Apparent molecular masses based on migration of protein standards are shown in kilodaltons.

incubation periods; however, $\mathrm{SHaPrP}$ differs from Mo, Gp, Bo and $\mathrm{Hu} \mathrm{PrP}$ at many other positions.

\section{Prion Disease Neuropathology in Gps}

Neuropathological analysis demonstrated that the human prion strains maintained many, but not all, of their characteristics after passage in Gps (Figure 4). The fine granular staining of $\mathrm{PrP}^{\mathrm{Sc}}$ deposits observed in Gps inoculated with sCJD is not exclusively specific for MM1 or MV1 sCJD but is also present in some other prion diseases. ${ }^{65}$ Frank amyloid plaques that are characteristic of human vCJD and GSS were absent in infected Gps, as determined by thioflavin S staining. However, large $\operatorname{PrP}^{\mathrm{Sc}}$ deposits, reminiscent of plaques, were found (Figure 4). Whether $\mathrm{GpPrP}^{\mathrm{sc}}$ is less amyloidogenic than $\mathrm{HuPrP}^{\mathrm{Sc}}$ remains to be determined. ${ }^{68}$ Both the neuropathology and progressive shortening of the incubation time indicate an adaption process, in which some of the phenotypic characteristics of the original inocula changed.

\section{Prions in the Tongue}

Because of several reports of prions in the tongues of experimentally infected animals, ${ }^{69-73}$ we measured the levels of $\operatorname{PrP}^{\mathrm{Sc}}$ in the tongues of Gps. Although $\operatorname{PrP}^{\mathrm{Sc}}$ was readily detectable in the brains of infected Gps by western blotting, the protease-resistant PrP signal in tongue was ambiguous because a shift in the molecular size of $\operatorname{PrP}^{\mathrm{Sc}}$ (cf. Figure 3) was not observed. One possibility is that the extended collagenase digestion used to liberate PrP from skeletal muscle also cleaved the $\mathrm{N}$-terminal residues of $\mathrm{GpPrP}^{\mathrm{Sc}}$ before limited proteolysis with PK (Figure 7). Detection of prions in tongue by bioassays would support this suggestion.

\section{Concluding Remarks}

Our findings suggest that Gps may be a useful model for the study of some aspects of human prion diseases. Unexpectedly, vCJD and BSE prions transmitted efficiently to Gps in contrast to earlier primary transmission studies of sCJD and GSS prions. The large deposits of $\operatorname{PrP}^{\mathrm{Sc}}$ surrounded by spongiform degeneration in the brains of Gps infected with vCJD prions were reminiscent of the neuropathological changes seen in the brains of vCJD patients. Currently, Gps probably provide the best animal model for studies of vCJD; whether Gps have detectable levels of prions in their lymphoid tissues require further investigation.

The susceptibility of Gps to human prions is particularly interesting in view of the development of $\operatorname{Tg}(\mathrm{MHu} 2 \mathrm{M}$, M111V,M165V,E167Q) mice that express a chimeric Hu/Mo PrP transgene and have an incubation period for human sCJD prions of $\sim 80$ days. ${ }^{39}$ Certainly, the creation of $\mathrm{Tg}(\mathrm{GpPrP})$ mice as well as mice expressing various chimeric $\mathrm{Gp} / \mathrm{Mo}$ PrP transgenes will be of interest. Whether Tg mice expressing GpPrP or some chimeric construct will exhibit incubation times more abbreviated than those found in $\mathrm{Tg}(\mathrm{MHu} 2 \mathrm{M}, \mathrm{M} 111 \mathrm{~V}, \mathrm{M} 165 \mathrm{~V}, \mathrm{E} 167 \mathrm{Q})$ mice inoculated with sCJD(MM1) prions remains to be determined.

\section{ACKNOWLEDGEMENTS}

We are grateful to Robert Will and James Ironside (National CJD Surveillance Unit, University of Edinburgh, UK) for brain samples of the VCJD patient, and to Jun Tateishi (Neurological Institute, Kyushu University, Fukuoka, Japan) for brain samples from the first passage of SCJD and GSS prions in Gps. This work was supported by a contract (NS02328) and by grants (AG010770 and AG031220) from the National Institutes of Health as well as gifts from the Hillblom Foundation, Sherman Fairchild Foundation, Schott Foundation for Public Education, and Robert Galvin.

\section{DISCLOSURE/CONFLICT OF INTEREST}

The authors declare no conflict of interest.

1. Gibbs Jr CJ, Gajdusek DC. Experimental subacute spongiform virus encephalopathies in primates and other laboratory animals. Science 1973;182:67-68.

2. Manuelidis EE. Transmission of Creutzfeldt-Jakob disease from man to the guinea pig. Science 1975;190:571-572.

3. Tateishi J, Sato Y, Koga M, et al. Experimental transmission of human subacute spongiform encephalopathy to small rodents. I. Clinical and histological observations. Acta Neuropathol (Berl) 1980;51:127-134.

4. Tateishi J, Kitamoto $T$, Hoque MZ, et al. Experimental transmission of Creutzfeldt-Jakob disease and related diseases to rodents. Neurology 1996;46:532-537.

5. Manuelidis E, Kim J, Angelo J, et al. Serial propagation of CreutzfeldtJakob disease in guinea pigs. Proc Natl Acad Sci USA 1976;73:223-227.

6. Pattison IH, Millson GC. Scrapie produced experimentally in goats with special reference to the clinical syndrome. J Comp Pathol 1961;71: 101-108.

7. Pattison $\mathrm{IH}$. The relative susceptibility of sheep, goats and mice to two types of the goat scrapie agent. Res Vet Sci 1966;7:207-212.

8. Dickinson AG, Meikle VMH, Fraser $\mathrm{H}$. Identification of a gene which controls the incubation period of some strains of scrapie agent in mice. J Comp Pathol 1968;78:293-299. 
9. Deleault NR, Harris $\mathrm{BT}$, Rees $\mathrm{JR}$, et al. Formation of native prions from minimal components in vitro. Proc Natl Acad Sci USA 2007; 104:9741-9746.

10. Wang $F$, Wang $X$, Yuan C-G, et al. Generating a prion with bacterially expressed recombinant prion protein. Science 2010;327:1132-1135.

11. Legname $\mathrm{G}$, Nguyen $\mathrm{H}-\mathrm{OB}$, Peretz $\mathrm{D}$, et al. Continuum of prion protein structures enciphers a multitude of prion isolate-specified phenotypes. Proc Natl Acad Sci USA 2006;103:19105-19110.

12. Tanaka M, Collins SR, Toyama BH, et al. The physical basis of how prion conformations determine strain phenotypes. Nature 2006;442: 585-589.

13. Colby DW, Giles K, Legname G, et al. Design and construction of diverse mammalian prion strains. Proc Natl Acad Sci USA 2009;106: 20417-20422.

14. Colby DW, Wain R, Baskakov IV, et al. Protease-sensitive synthetic prions. PLoS Pathog 2010;6:e1000736.

15. Bocharova OV, Makarava N, Breydo L, et al. Annealing prion protein amyloid fibrils at high temperature results in extension of a proteinase K-resistant core. J Biol Chem 2006;281:2373-2379.

16. Buschmann A, Gretzschel A, Biacabe AG, et al. Atypical BSE in Germany-proof of transmissibility and biochemical characterization. Vet Microbiol 2006;117:103-116.

17. Biacabe AG, Laplanche JL, Ryder S, et al. Distinct molecular phenotypes in bovine prion diseases. EMBO Rep 2004;5:110-115.

18. Casalone $C$, Zanusso $G$, Acutis $P$, et al. Identification of a second bovine amyloidotic spongiform encephalopathy: molecular similarities with sporadic Creutzfeldt-Jakob disease. Proc Natl Acad Sci USA 2004;101:3065-3070.

19. Yamakawa $\mathrm{Y}$, Hagiwara $\mathrm{K}$, Nohtomi $\mathrm{K}$, et al. Atypical proteinase K-resistant prion protein ( $\mathrm{PrP}^{\mathrm{res}}$ ) observed in an apparently healthy 23-month-old Holstein steer. Jpn J Infect Dis 2003;56:221-222.

20. Richt JA, Kunkle RA, Alt $D$, et al. Identification and characterization of two bovine spongiform encephalopathy cases diagnosed in the United States. J Vet Diagn Invest 2007;19:142-154.

21. Eloit M, Adjou K, Coulpier M, et al. BSE agent signatures in a goat. Vet Rec 2005;156:523-534.

22. Heaton MP, Keele JW, Harhay GP, et al. Prevalence of the prion protein gene E211K variant in US cattle. BMC Vet Res 2008;4:25.

23. Bessen RA, Marsh RF. Distinct PrP properties suggest the molecular basis of strain variation in transmissible mink encephalopathy. J Virol 1994;68:7859-7868.

24. Bessen RA, Kocisko DA, Raymond GJ, et al. Non-genetic propagation of strain-specific properties of scrapie prion protein. Nature 1995; 375:698-700.

25. Telling GC, Parchi P, DeArmond SJ, et al. Evidence for the conformation of the pathologic isoform of the prion protein enciphering and propagating prion diversity. Science 1996;274:2079-2082.

26. Safar J, Wille $\mathrm{H}$, Itri $\mathrm{V}$, et al. Eight prion strains have $\operatorname{PrP}^{\mathrm{Sc}}$ molecules with different conformations. Nat Med 1998;4:1157-1165.

27. Peretz $D$, Williamson $R A$, Legname $G$, et al. $A$ change in the conformation of prions accompanies the emergence of a new prion strain. Neuron 2002;34:921-932.

28. Scott $M$, Foster $D$, Mirenda $C$, et al. Transgenic mice expressing hamster prion protein produce species-specific scrapie infectivity and amyloid plaques. Cell 1989;59:847-857.

29. Prusiner SB, Scott M, Foster D, et al. Transgenetic studies implicate interactions between homologous PrP isoforms in scrapie prion replication. Cell 1990;63:673-686.

30. Race RE, Priola SA, Bessen RA, et al. Neuron-specific expression of a hamster prion protein minigene in transgenic mice induces susceptibility to hamster scrapie agent. Neuron 1995;15:1183-1191.

31. Telling GC, Scott M, Mastrianni J, et al. Prion propagation in mice expressing human and chimeric PrP transgenes implicates the interaction of cellular PrP with another protein. Cell 1995;83:79-90.

32. Manson JC, Jameison $\mathrm{E}$, Baybutt $\mathrm{H}$, et al. A single amino acid alteration (101 I) introduced into murine PrP dramatically alters incubation time of transmissible spongiform encephalopathy. EMBO J 1999;18:6855-6864.

33. Barron RM, Thomson V, Jamieson $E$, et al. Changing a single amino acid in the N-terminus of murine PrP alters TSE incubation time across three species barriers. EMBO J 2001;20:5070-5078.

34. Scott MR, Peretz D, Nguyen $\mathrm{H}-\mathrm{OB}$, et al. Transmission barriers for bovine, ovine, and human prions in transgenic mice. J Virol 2005; 79:5259-5271.
35. Castilla J, Gonzalez-Romero D, Saa P, et al. Crossing the species barrier by $\mathrm{PrP}^{\mathrm{SC}}$ replication in vitro generates unique infectious prions. Cell 2008;134:757-768.

36. Tremblay P, Ball HL, Kaneko K, et al. Mutant PrP $\mathrm{P}^{\mathrm{Sc}}$ conformers induced by a synthetic peptide and several prion strains. J Virol 2004;78: 2088-2099.

37. Korth C, Kaneko K, Groth D, et al. Abbreviated incubation times for human prions in mice expressing a chimeric mouse-human prion protein transgene. Proc Natl Acad Sci USA 2003;100:4784-4789.

38. Ancill RJ. The blood volume of the normal guinea-pig. J Physiol 1956;132:469-475.

39. Giles $\mathrm{K}$, Glidden DV, Patel $\mathrm{S}$, et al. Human prion strain selection in transgenic mice. Ann Neurol 2010;68:151-161.

40. Buschmann A, Groschup MH. Highly bovine spongiform encephalopathy-sensitive transgenic mice confirm the essential restriction of infectivity to the nervous system in clinically diseased cattle. J Infect Dis 2005;192:934-942.

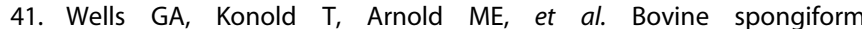
encephalopathy: the effect of oral exposure dose on attack rate and incubation period in cattle. J Gen Virol 2007;88:1363-1373.

42. Marsh RF, Kimberlin RH. Comparison of scrapie and transmissible mink encephalopathy in hamsters. II. Clinical signs, pathology, and pathogenesis. J Infect Dis 1975;131:104-110.

43. Kimberlin R, Walker C. Characteristics of a short incubation model of scrapie in the golden hamster. J Gen Virol 1977;34:295-304.

44. Chandler RL. Encephalopathy in mice produced by inoculation with scrapie brain material. Lancet 1961;277:1378-1379.

45. Bruce M, Chree A, McConnell I, et al. Transmission of bovine spongiform encephalopathy and scrapie to mice: strain variation and the species barrier. Philos Trans R Soc Lond B Biol Sci 1994;343: 405-411.

46. Carlson GA, Ebeling C, Yang S-L, et al. Prion isolate specified allotypic interactions between the cellular and scrapie prion proteins in congenic and transgenic mice. Proc Natl Acad Sci USA 1994;91:5690-5694.

47. Prusiner SB, Cochran SP, Groth DF, et al. Measurement of the scrapie agent using an incubation time interval assay. Ann Neurol 1982;11:353-358.

48. Carlson GA, Kingsbury DT, Goodman PA, et al. Linkage of prion protein and scrapie incubation time genes. Cell 1986;46:503-511.

49. Safar JG, Scott M, Monaghan J, et al. Measuring prions causing bovine spongiform encephalopathy or chronic wasting disease by immunoassays and transgenic mice. Nat Biotechnol 2002;20: 1147-1150.

50. Safar JG, Geschwind MD, Deering C, et al. Diagnosis of human prion disease. Proc Natl Acad Sci USA 2005;102:3501-3506.

51. Kascsak RJ, Rubenstein R, Merz PA, et al. Mouse polyclonal and monoclonal antibody to scrapie-associated fibril proteins. J Virol 1987;61:3688-3693.

52. Muramoto T, DeArmond SJ, Scott $M$, et al. Heritable disorder resembling neuronal storage disease in mice expressing prion protein with deletion of an $\alpha$-helix. Nat Med 1997;3:750-755.

53. Premzl M, Gamulin V. Comparative genomic analysis of prion genes. BMC Genomics 2007;8:1-14.

54. van Rheede T, Smolenaars MM, Madsen O, et al. Molecular evolution of the mammalian prion protein. Mol Biol Evol 2003;20:111-121.

55. Telling GC, Scott M, Hsiao KK, et al. Transmission of Creutzfeldt-Jakob disease from humans to transgenic mice expressing chimeric humanmouse prion protein. Proc Natl Acad Sci USA 1994;91:9936-9940.

56. Fraser $\mathrm{H}$, Bruce ME, Chree $A$, et al. Transmission of bovine spongiform encephalopathy and scrapie to mice. J Gen Virol 1992;73:1891-1897.

57. Masters CL, Gajdusek DC, Gibbs Jr CJ. Creutzfeldt-Jakob disease virus isolations from the Gerstmann-Sträussler syndrome. Brain 1981; 104:559-588.

58. Wells GAH, Wilesmith JW. The neuropathology and epidemiology of bovine spongiform encephalopathy. Brain Pathol 1995;5:91-103.

59. Wells GAH, Wilesmith JW, McGill IS. Bovine spongiform encephalopathy: a neuropathological perspective. Brain Pathol 1991;1:69-78.

60. Foster JD, Parnham D, Chong A, et al. Clinical signs, histopathology and genetics of experimental transmission of BSE and natural scrapie to sheep and goats. Vet Rec 2001;148:165-171.

61. Parchi $\mathrm{P}, \mathrm{Chen} \mathrm{SG}$, Brown $\mathrm{P}$, et al. Different patterns of truncated prion protein fragments correlate with distinct phenotypes in P102L 
Gerstmann-Sträussler-Scheinker disease. Proc Natl Acad Sci USA 1998;95:8322-8327.

62. Brown $\mathrm{P}$, Gibbs Jr CJ, Rodgers-Johnson $\mathrm{P}$, et al. Human spongiform encephalopathy: the National Institutes of Health series of 300 cases of experimentally transmitted disease. Ann Neurol 1994;35: 513-529.

63. Tateishi J, Kitamoto T, Doh-ura K, et al. Immunochemical, molecular genetic, and transmission studies on a case of GerstmannSträussler-Scheinker syndrome. Neurology 1990;40:1578-1581.

64. Tateishi J. Transmission of human prion disease to rodents. Semin Virol 1996;7:175-180.

65. Gambetti P, Kong Q, Zou W, et al. Sporadic and familial CJD: classification and characterisation. Br Med Bull 2003;66:213-239.

66. Furuoka $\mathrm{H}$, Horiuchi $\mathrm{M}$, Yamakawa $\mathrm{Y}$, et al. Predominant involvement of the cerebellum in guinea pigs Infected with bovine spongiform encephalopathy (BSE). J Comp Pathol 2011;144:269-276.

67. Giles K, Glidden DV, Beckwith R, et al. Resistance of bovine spongiform encephalopathy (BSE) prions to inactivation. PLoS Pathog 2008;4: e1000206.

68. DeArmond SJ, Kretzschmar HA, Prusiner SB. Prion diseases. In: Graham DI, Lantos PL (eds). Greenfield's Neuropathology, 7th edn. Hodder Arnold: London, 2002, pp 273-323.
69. Bartz JC, Kincaid AE, Bessen RA. Rapid prion neuroinvasion following tongue infection. J Virol 2003;77:583-591.

70. Thomzig A, Kratzel C, Lenz G, et al. Widespread PrP ${ }^{S c}$ accumulation in muscles of hamsters orally infected with scrapie. EMBO Rep 2003;4:530-533.

71. DeJoia C, Moreaux B, O'Connell K, et al. Prion infection of oral and nasal mucosa. J Virol 2006:80:4546-4556.

72. Bartz JC, Dejoia C, Tucker $\mathrm{T}$, et al. Extraneural prion neuroinvasion without lymphoreticular system infection. J Virol 2005;79: 11858-11863.

73. Mulcahy ER, Bartz JC, Kincaid $A E$, et al. Prion infection of skeletal muscle cells and papillae in the tongue. J Virol 2004;78:6792-6798.

74. Emanuelsson O, Brunak S, von Heijne G, et al. Locating proteins in the cell using TargetP, SignalP and related tools. Nat Protoc 2007;2: 953-971.

75. Eisenhaber B, Bork P, Eisenhaber F. Prediction of potential GPI-modification sites in proprotein sequences. J Mol Biol 1999;292:741-758.

76. Laemmli UK. Cleavage of structural proteins during the assembly of the head of bacteriophage T-4. Nature 1970;227:680-685.

77. Scott MR, Will R, Ironside J, et al. Compelling transgenetic evidence for transmission of bovine spongiform encephalopathy prions to humans. Proc Natl Acad Sci USA 1999;96:15137-15142. 